\title{
EL ALTAR MAYOR Y EL DE REYES DE LA CATEDRAL DE VALLADOLID, MORELIA ${ }^{1}$
}

\section{Punto de partida}

Las catedrales mexicanas de la época novohispana perdieron gran parte de su configuración barroca original. Su historia, a partir de mediados del siglo pasado, es la de su desmantelamiento paulatino. Sólo conservan el coro en la nave central las de México, Puebla y Oaxaca; todas han perdido su altar mayor exento o ciprés barroco que se unía al coro por medio de una crujía o balaustrada, y sólo México y Puebla conservan en el ábside, al fondo, un gran retablo que adornaba la capilla real. ${ }^{2}$

Morelia - la antigua Valladolid de Michoacán-, a la que se ornamentara a lo largo del siglo XVIII, es hoy quizás la mấs desnuda del antiguo esplendor que aún contemplara en 1841 Madame Calderón de la Barca:

"Su riqueza es todavía maravillosa, no obstante de que durante las guerras civiles la han desposeído de unos 32.000 marcos de plata. Deslumbra el oro y la plata del altar mayor. La balaustrada que le une al coro y las columnas que la sostienen son de plata pura. El coro mismo es de una extraordinaria belleza, lo es también su reja, de madera tallada y una de las puertas es de plata maciza). ${ }^{3}$

1 Es esta la versión corregida y aumentada del artículo del mismo título publicado en 1988 en \&elaciones $\bowtie$, núm. 34. A esta última alude la glosa documer1tal y reconstrucción ideal del ciprés barroco de la catedral de Valladolid que realizara el arquitecto Manuel González Galván. González Galván, Manuel: Una glosa reconstructiva ideal. EL antiguo ciprés barroco de la catedral de Morelia. «Anales del Instituto de Investigaciones Estéticas», núm. 59, México, 1988, páginas 93-100.

2 Manrique, Jorge Alberto: Catedrales desnudas: Morelia, en «La Jornada», 8 de septiembre de 1988.

3 Calderón de la Barca, Madame: Recorrido por Michoacán, en La vida en México. México, 1982, pág. 38. 
Tan sólo cuatro años después, el 6 de agosto de 1845, día de la Transfiguración, fue estrenado un altar mayor al parecer ya de gusto neoclásico, y el 23 de septiembre de 1858, ante el fragor del radicalismo liberal, «fue asaltada la iglesia por la tropa armada para despojarla de la crujía y toda la demás plata que tenía». ${ }^{4}$ Finalmente, en 1897 el arzobispo Arciga y Ruiz de Chávez, con asesoría del italiano Claudio de Molina, determinó renovar la decoración interior trasladando el coro al espacio antes ocupado por el altar de reyes, en el ábside. ${ }^{5}$

Intento aquí contribuir al rescate de la tradición retablística novohispana en Morelia por lo que hace a los altares mayor y de reyes de su catedral, una de las más importantes de Hispanoamérica. La ocasión de haber dado con escasos aunque ricos documentos en algunos archivos de esa ciudad se debió, en un principio, al estudio que realicé de la gestión michoacana del obispo Pedro Anselmo Sánchez de Tagle entre los años de 1758 y 1772. Ella, por tanto, constituye el ambiente histórico pertinente para hablar no sólo de los altares mayor y de reyes que se mandaran hacer, sino también de otras realizaciones tales como el seminario tridentino, la escuela de infantes de catedral, la iglesia de San José y la culminación del actual edificio de la mitra. Todos engalanaron la capital episcopal michoacana durante aquel período dieciochesco.

Tal florecimiento de las artes, la educación y las instituciones ha de entenderse como manifestación de la honda vocación humanística de aquel obispo. Pero también como tradición de gobierno diocesano, mucho más orientada a reforzar las formas socio-culturales de los grupos locales, que a acatar incondicionalmente las disposiciones reformistas de la monarquía borbónica. Esta tendía a socavar la relativa autonomía fiscal y administrativa de las iglesias catedrales en los dominios de América.

Por otro lado, a la secularización de las doctrinas hasta entonces atendidas por frailes y la expulsión de los jesuitas educa-

4 Archivo del Cabildo Catedral de Morelia (en adelante. A.C.C.M.), Actas capitulares, Libro 52. Sesiones del 3 y 20 de junio de 1845.

5 A.C.C.M., Actas capitulares, Libro 70. Sesión del 8 de abril de 1897. 
dores en 1767, correspondió en Michoacán un fortalecimiento de la presencia moral y material del clero diocesano, notoria por la edificación del seminario tridentino entre 1760 y 1770. Ante los frecuentes rumores sobre la expropiación de los diezmos a las iglesias, la mitra vallisoletana reaccionó desde 1766-1768 dando a sus caudales de fábrica un destino seguro: la ornamentación de su catedral y la reforma de sus instituciones litúrgico-musicales. Todo ello con cierta premura, «...no sea que el señor visitador [José de Gálvez] que se halla en México como más despótico, quiera... imponer y ejecutar sus condiciones». ${ }^{\circ}$

El dramatismo prevaleció como tono en el perfil administrativo de la gestión de Sánchez de Tagle y el barroco fue el espíritu que animó la expresión de las diversas formas de vida social hen. chidas de religiosidad. Estas formas traducían el carácter y la dignidad regionales y en última instancia reflejaban afanes propios del catolicismo postridentino de la Nueva España. ${ }^{7}$

Antes de ver los pormenores de la concepción y forja de los altares mayor y de reyes conviene insistir en el carácter de signo de estas obras, proyectadas por la jerarquía eclesiástica, entre otras cosas, para defender sus propias tradiciones de gobierno y administración. Ha de ponderarse también la presencia pública y duradera de este tipo de realizaciones. Se daban en medio de una sociedad volcada hacia lo sagrado en expresión mágica y multicolor, crecientemente ornamental, donde construir un altar mayor significaba edificar la piedra fundamental, el trono de Cristo. ${ }^{8}$ Por otro lado al esculpir el altar de los reyes se evocaba la autoridad del monarca y su patrocinio sobre las iglesias de Indias. Pero igual-

6 Mazín, Oscar: Entre dos majestades, el obispo y la iglesia del gran Michoacán ante las reformas borbónicas, 1758-1772. Zamora, Michoacán, 1987. capítulo quinto. A.C.C.M., Actas capitulares, Libro 26. Sesión del 20 de septiembre de 1764

7 Para periodizar se suelen tomar en cuenta las gestiones de los obispos. Sin lembargo el cabildo eclesiástico, en su carácter de cuerpo colegiado permanente, acuñaba los saberes de la tradición artística. Así parece por lo menos en el caso de Michoacán. Por su parte los obispos se apoyaban en las disposiciones capitulares, bien fuera para impulsarlas, desviarlas o detenerlas.

8 Estrada de Gerlero, Elena: «Altar mayor», en Catedral de México, patrimonio artístico y cultural. México, 1986, págs. 453-465. 
mente se recordaba la misión de éste al servicio de la Majestad divina.

\section{ANTECEDENTES DE LOS ALTARES MAYOR Y DE REYES}

Nuestro relato se inicia en septiembre de 1764 con el viaje del tesorero del cabildo catedral de Valladolid, el poblano Ricardo Gutiérrez Coronel, a las ciudades de México y Puebla. ${ }^{9}$ El obispo Sánchez de Tagle estaba decidido a emprender un conjunto de obras en el interior de la catedral, cuya fábrica material se había concluido en 1745. En consecuencia, pidió a Gutiérrez Coronel poco antes de salir éste que «tomase información, diseño o montea del altar mayor de la catedral de México y razón del mejor oficial que pudiera hacer otro igual y que fuera del agrado del cabildo». ${ }^{10}$

Luego de algunos días de descanso en Puebla, Gutiérrez Coronel encargó al mayordomo del obispo Fabián y Fuero, don

9 Por lo que hace a la tradición de la plástica en una catedral novohispana, recaía en el tesorero dignidad del cabildo la administración y ejecución de los principales proyectos de obras. Se ocupaba de la contratación de los maestros y sobrestantes, así como de la compra de los materiales, y rendía cuentas anuales de los gastos de fábrica espiritual ante el cabildo. Finalmente recibían la aprobación del obispo.

10 A.C.C.M., Actas capitulares, Libro 26. Sesión del 20 de septiembre de 1764. Este altar mayor no fue el primero con el que contó la catedral de Valladolid. En 1706, a un año de haberse ocupado y consagrado la nueva iglesia catedral, el obispo Escalante y Colombres dejó en manos del cabildo la contratación de un maestro (José?) Cardoso, para que hiciera un marco para el altar mayor, en cuyo respaldo se pondría un enorme lienzo del triunfo de la iglesia y nave de San Pedro. A.C.C.M., expediente de 1706. El obispo Escalante al deán y cabildo, 3 de marzo de 1706. Más tarde, en 1717, se hicieron trámites para contratar nuevo aitar mayor «con todas las estatuas que son 12 apóstoles; la del Salvador en el segundo cuerpo; en el tercero la de la Virgen, y len el primero la custodia y trono de plata; y en el remate la del señor san Miguel». El maestro por el cual se inclinó la mayoría era (Sebastián?) Cardoso, ensamblador. Parece que este altar mayor se concluyó en 1719. A.C.C.M., Actas capitulares, libro 16, sesión del 27 de septiembre de 1717. Por otra parte, la gestión de Sánchez de Tagle no fue la única en que se contrataron varias obras a la vez. En 1734 se contrataron simultáneamente la reja del coro con sus antepechos, crujía y circuito del presbiterio, un enorme sepulcro o monumento, y la lámpara o candil monumental para el altar mayor. En los primeros trabajó iel maestro latonero Felipe Antonio de la Vega, vecino de México. El monumento fue ejecutado por Felipe de Ureña, y la lámpara por el maestro Diego de Vargas. (A.C.C.M., Expediente de 1734. Autos de la neja y de la crujía). 
Miguel Ballejo (sic), un plano para el altar mayor. Cuando lo hubo obtenido, el tesorero de la mitra de Valladolid emprendió el viaje de regreso. En la ciudad de México se entrevistó con donl Isidoro Vicente de Balbás, «maestro arquitecto, escultor y dorador», " autor de los espléndidos retablos de Santa Prisca de Taxco donde al parecer había vivido hasta aproximadamente 1758, al quedar terminada aquella iglesia. Gutiérrez Coronel también le encargó un plano para el altar mayor que le sería enviado más tarde a Valladolid. ${ }^{12}$ Balbás no podía viajar a Michoacán en el término de un mes, según se le pedía, pues hasta aquel momento el arzobispo Rubio y Salinas le tenía ejecutando una obra en el Sagrario metropolitano. ${ }^{13}$

"Y aún habiendo terminado dicha obra... finalizaba yo algunas cosas de poco monto de tiempo que su ilustrísima pretendía hacer para más adorno de su obra». ${ }^{14}$

Cuando estuvo de vueltạ en Valladolid, Gutiérrez informó al cabildo catedral que prefería no mostrar el plano del artífice de Puebla, hasta no recibir el que había dejado haciendo en México. Con todo recomendó, no sin cierto orgullo por su tierra, que para el altar mayor se hicieran «gradas y ramilletes como se usan en la ciudad de Puebla y que dan mucho lucimiento en las funciones». ${ }^{15}$

11 Tovar de Tenesa, Guillermo: México barroco. México, 1981, pág. 88. Ver también el artículo de Amerlinck, María Concepción: Jerónimo de Balbás, artista de vanguardia y el retablo de la Concepción de la ciudad de México. BBoletín del Instituto de Investigaciones Estéticas», núm. 7, México, 198ð.

12 A.C.C.M., Actas capitulares, Libro 26. Sesión del 16 de enero de 1765.

13 Se trataba muy probablemente del altar mayor hoy desaparecido. A.C.C.M., Expedientes de actas capitulares, 1770. Isidoro Vicente de Balbás al cabildo catecural de Valladolid. Carta sin fecha. Las catedrales novohispanas competían entre sí por los mejores artistas y las mejores condiciones económicas. Ya en 1741 don Jerónimo de Balbás, padre adoptivo de Isidoro Vicente, tuvo que renunciar al título de maestro mayor de la fábrica de torres y fachadas de la catedral de Valladolid, pues se había comprometido a trabajar simultáneamente el altar mayor o ciprés de la catedral de México. Mazín, Oscar; Sigaut, Nelly: El cabildo eclesiástico de Valladolid y la construcción de las torres y fachadas de su catedral. Ponencia sustentada en el primer coloquio del Comité Mexicano de Historia del Arte, mayo $16-18$ de 1990 .

14 Ibidem.

15 A.C.C.M., Actas capitulares. Sesión del 16 de enero de 1765. 


\section{VIENTOS DE BORRASCA}

1765 fue un año difícil para la catedral de Michøacán, pues las presiones fiscales estuvieron a la orden del día. Hasta entonces la iglesia administraba las dos novenas partes destinadas al rey del total de diezmos. Esta concesión para el cobro y administración de los «reales novenos» contribuyó a aumentar en un $10 \%$ las rentas del ramo de fábrica espiritual entre 1760 y $1765 .{ }^{16}$ Sin embargo, en este último año vencía el contrato y corrían ya rumores de que en adelante la Corona pondría sus propios administradores. Todo esfuerzo por mejorar la postura del arrendamiento de este ramo resultó inútil y el 20 de agosto se nombró un administrador del rey. ${ }^{17}$

La frecuencia e impopularidad de las presiones fiscales, más las dificultades internas como la pasada epidemia de matlazáhuatl y una primera e impopular leva para la formación de milicias, crearon un clima de franca desaprobación, recelo y temor en la jerarquía michoacana. Por otra parte, se tomaron decisiones tendentes a reforzar el proyecto diocesano por lo que toca a su dimensión cultural.

En conformidad con su cabildo, el obispo Sánchez de Tagle dispuso que los caudales del ramo de fábrica se destinaran de inmediato a los siguientes conjuntos de obras en la catedral: Primero, la construcción de un edificio para «nuevo bautisterio con pila bautismal y casa para el vicario de catedral que se pondría encima de la sacristía y del nuevo bautisterio». ${ }^{18}$ En segundo

16 Morin, Claude: Michoacán en la Nueva España del siglo XVIII. México. 1979, pág. 137. Archivo General de Indias, México, 2.552.

17 Mazín, Entre dos majestades..., pág. 116.

18 A.C.C.M., Actas capitulares, libros 15 y 16. Por lo que hace al conjunto de edificios anexos al cuerpo de la iglesia catedral y que miran al poniente, hubo por lo menos tres etapas de construcción. La primera se inició en julio de 1710 con sla obra y fábrica de las oficinas para la sacristía, sala del tesoro, caja, trascaja, contaduría y vivienda del sacristán mayor y otras piezas necesarias para el servicio de esta iglesia». Estuvo a cargo del maestro de arquitectura Nicolás de Covarrubias, residente en Valladolid, y ya en junio de 171z se cerraban algunas bóvedas. Pero el 27 de enero de 1713 se determinó que perfeccionadas las oficinas que estaban hechas, se suspendiera la obra. La segunda etapa tuvo lugal 
lugar, un remate para la torre poniente de catedral que se hallaba derruido por un rayo desde $1754 .^{19} \mathrm{Y}$ por último nuevo altar mayor, altar de los reyes y una crujía o balaustrada de plata que sustituyera la de bronce que de su propio peculio mandara hacer en 1734 el obispo Escalona y Calatayud. ${ }^{20}$ Para la ejecución de estas últimas obras se celebraría un concurso de oposición al que acudirían maestros de arte de varias regiones.

Todo fue ordenado sin licencia real, pues se temía que «el rey entrara en la administración de los caudales de fábrica del cual son únicos administradores el obispo y su cabildo». ${ }^{21}$

\section{LA TORRE DE PONIENTE}

El 29 de enero de 1766 el tesorero Gutiérrez Coronel propuso al cabildo de parte del obispo que se mandara componer la arruinada torre poniente de la catedral. Años antes la había destacado en su diario de viaje fray Francisco de Ajofrín: «la cate-

en 1744, cuando el maestro poblano José de Medina finalizaba las torres y fachadas de la catedral. Como sobraran recursos, el deán Juan Manuel Solano propuso por entonces al cabildo que se acabaran «las oficinas altas que están comenzadas sobre la clavería, contaduría y lo demás...», lo cual se aprobó previo reconocimiento de la planta que para dichas oficinas comenzadas presentara Medina. El deán recomendó «añadírseles arcos para que quedasen más amplias». A.C.C.M., Actas capitulares, libro 20. Sesiones del 6 y 13 de noviembre de 1744. En cuanto al magníflco edificio con cúpula elíptica y claustros alto $\mathbf{y}$ bajo que hoy se conoce como «la mitra», no consta de manera precisa si también fue ejecutado por Medina entre 1744 y 1746. Las escasas noticias y la unidad de estilo con la obra de fachadas y torres así parecen sugerirlo. La tercera etapa sería la del proyecto de 1765 para nuevo bautisterio y casa para el vicario de catedral. Pero sólo consta haberse ejecutado la pila bautismal, que por cierto salió errada. Por su parte, el arquitecto Manuel González Galván nos informa que sla mitra fue edificada a iniciativa del obispo Sánchez de Tagle, pero no presenta evidencia documental. «Monografías de Arte Sacro», núms. 10-11, agosto de 1981-febrero de 1982.

19 A.C.C.M., Actas capitulares, Libro 27. Sesión del 15 de septiembre de 1766.

20 A.C.C.M., Actas capitulares, libro 20. En la sesión del 24 de octubre de 1747 el cabildo consideró que cualquier gasto para componer la reja del coro y crujía sería infructuoso, «pues siempre quedará defectuosa [la reja], por su mala disposición y fábrica». Se acordó por entonces no ponerle la mano, chasta que mandados pagar los 10.000 pesos que el sr. Escalona donó para dicha reja y crujia, se determine el que se haga de nuevo».

¿1 Mazín, Entre dos majestades..., capítulo tercero. A.C.C.M., Actas capitulares, Libro 28. Sesión del 26 de agosto de 1768. 
dral vallisoletana domina todo el panorama, aunque una torre había perdido dos de sus cuerpos a causa de un rayo». ${ }^{22}$

Durante la temporada de secas de 1766 fue el maestro Francisco Gudiño quien reparó el segundo cuerpo y confeccionó la linternilla y remate de la torre occidental o del reloj que hoy se distingue de la oriental o de las campanas. ${ }^{23}$ En la sesión del cabildo catedral del 15 de septiembre de 1766 dieron los peritos Ascencio de Anaya y Tomás de Huerta su informe sobre la conclusión de los trabajos:

“El maestro Gudiño de Querétaro ha hecho la fábrica de dicho remiendo con todo magisterio...reforzando las cuarteaduras del segundo cuerpo de la torre occidental con las reflexiones del arte; que asimismo los remiendos de las cornisas con toda la uniformidad en la correspondencia de sus miembros, que la nueva construcción de su tercer cuerpo o linternilla guarda uniformidad con la torre de las campanas, sin que ni en sus ornamentos desdiga en nada la una de la otra, guardando igual simetría en todo hasta en su pilarejo, pinjante o remate, observando en lo ejecutado en dicha obra los preceptos del arte, por lo que se hallan se le debe recibir y aprobar dicha obra». ${ }^{24}$

22 Ajofrín, Francisco de: Diario del viaje a la Nueva España. México, 1986. pág. 93 .

23 Era Francisco Gudiño maestro de arquitectura oriundo de Guadalajara. Al contratársele en 1766 para trabajar en la catedral de Valladolid residía en Querétaro, en donde debía terminar algunas obras. En su obra citada, Guillermo Tovar de Teresa le atribuye los arbotantes o botareles «rococó» (sic) del exterior de la iglesia de Santa Rosa de Viterbo en Querétaro. Según veremos, Gudiño no sólo fue contratado en 1773 para ejecutar el altar de los reyes de la catedral michoacana, sino que fue maestro mayor de las obras pendientes de altar mayor y crujía en la misma iglesia. A.C.C.M., Actas capitulares, Libro 30. Sesión del 4 de agosto de 1773. Cuentas que dio Bartolomé Castillo, maestro de herrería, al superintendente de las obras de catedral. Archivo Histórico Manuel Castañeda Ramírez (en adelante A.H.M.C.R.), Casa de Morelos, Negocios diversos, legajo 89, 1776. Asimismo, Gudiño fue contratado en 1773 por la ciudad de Valladolid para construir el edificio destinado para alhóndiga. Archivo de Notarías de Morelia, Protocolos, vol. 136, 1773.

24 A.C.C.M., Actas capitulares, Libro 27. Sesión del 15 de septiembre de 1766. Ascencio de Anaya, cantero, tal vez trabajó en las fachadas de la catedral te Valladolid en 1743. Ramírez Montes, Mina: La escuadra y el cincel. México, 1987, págs. 15. Tomás de Huerta fue contratado en $\mathbf{1 7 6 0}$ como alarife de las obras del seminario tridentino de Valladolid. Antes (?) trabajó en la fábrica del colegio de la Compañía de Jesús de la misma ciudad. Mazín, Entre dos Majestades..., pág. 53. 


\section{H $\Lambda$ CIA LOS ALTARES MAYOR Y DE REYES}

Los meses siguientes vieron los preparativos para el concurso de oposición. ${ }^{25}$ Recordemos que el proyecto no sólo incluía los altares mayor y de reyes, sino también una nueva crujía que uniera el coro con el presbiterio y que rodeara este último; además había que «poner escudos en el antepecho y copetes del coro», así como ejecutar un acceso de herrería para la capilla real. ${ }^{26}$

Ahora bien, las fuentes permiten considerar que los artífices concursantes no estaban obligados a presentar planos para todas estas obras. Alguno dijo poder ejecutar todo por un mismo precio pero según veremos, al final hubo un solo maestro mayor para dirigir los trabajos.

Tocante a la capilla real, el cabildo eclesiástico propuso que cl frontal del altar de reyes se hiciera de plata, y en cuanto al altar mayor la mayoría de los prebendados se inclinó por que éste fuera de madera. Se acordó se pusieran luego los edictos convocatorios para «aquellos maestros que quisiesen hacer postura de superintendencia de dicha fábrica». ${ }^{27}$ Consecuentemente, se recibirían los proyectos a lo largo de 1767 para que en los primeros meses del año siguiente se otorgara la superintendencia al elegido.

Por la documentación se advierte una tenaz afirmación de la tradición administrativa local del cabildo catedral frente al centralismo burocrático, ya que «temían que su majestad y el señor virrey trataran de echar mano de los caudales de las iglesias para socorrer las urgencias que le asisten a la corona y que antes que esto se verifique, sería bueno se pusiere por obra la fábrica del

25 Los cabildos eclesiásticos ejercían los criterios del ahorro y la calidad mediante la competencia artística. Era el concurso de oposición el recurso privilegiado para mantener y enriquecer las tradiciones catedralicias no sólo de indole artística, como la musical y la plástica, sino las propiamente administrativas. En consecuencia, el éxito dependía del buen manejo del principal ramo de gastos, llamado de fábrica espiritual, único sobre el cual tenían un control relativamente autónomo los obispos y su cabildo.

26 A.H.M.C.R., Caja de Morelos, Negocios diversos, legajo 89. Cuentas de Bartolomé Castillo, 1776.

27 A.C.C.M., Actas capitulares, Libro 27. Sesión del 25 de noviembre de 1766. 
altar mayor de Valladolid que está pendiente de la determinación de su señoría ilustrísima». ${ }^{28}$

Del concurso no quedó memoria escrita y acaso se efectuaría discretamente ya muy entrado el año 1768. Por entonces quedó vacante el cargo de contador mayor de la catedral, el cual se proveía mediante remate de postura en arrendamientos celebrados en la ciudad de México. El obispo Sánchez de Tagle ordenó que esta vez no se pusieran los edictos, y el nuevo contador fue reclutado calladamente para así preservar los intereses de la mitra. ${ }^{29}$

Con todo, hasta la navidad de 1768 la catedral michoacana retuvo el aliento, pues temía que se quitase definitivamente a la iglesia la administración del diezmo y en adelante se encargara su cobranza y distribución a oficiales reales. Fue en 1775 cuando esto llegó a ocurrir.

\section{LOS ARTÍFICES DEL CONCURSO}

Los proyectos de los que se conserva alguna memoria histórica fueron tres. Todos incluyeron planos o «mapas» para el altar mayor, y sólo dos se refirieron al altar de reyes en su correspondencia. Desafortunadamente las plantas y alzados se hallan extraviados en algún archivo o perdidos sin remedio. Sólo nos queda el registro de las cartas con el texto de una de ellas, algunas cuentas, y la descripción verbal que de su altar mayor dirigiera al cabildo de Valladolid el propio don Isidoro Vicente de Balbás.

Al primero de los artífices le hemos dejado en Puebla. Se trataba de don Miguel Ballejo, pariente y segundo mayordomo del obispo Fabián y Fuero. Había delineado desde 1765 el mapa y condiciones «para la obra del tabernáculo o ciprés de la catedral» de Valladolid y ahora, en 1768, pedía al capítulo diocesano honorarios por su trabajo. Sin embargo, en mayo «se le dieron 12 pesos

28 A.C.C.M., Actas capitulares, Libro 27. Sesión del 10 de marzo de 1767.

29 Mazin, Entre dos majestades..., capitulo quinto. A.C.C.M., Actas capitulares, Libro 26. Sesión del 5 de diciembre de 1766. 
por sus mapas, pues estaban errados y eran de baja calidad». El proyecto de Ballejo quedó descalificado.

El otro candidato era don Ignacio Mariano de las Casas, queretano. El cabildo le había escrito, «así como a otros artistas de aquella ciudad y de la de Celaya y otras partes para que hagan sus mapas de la obra, en la inteligencia de que no se les ha de pagar, sino sólo les sirva de oposición». Tendrían un año y medio de plazo y se gastarían sólo para el altar mayor de 11.000 a 12.500 pesos. ${ }^{30}$ Las cartas e informes que recomendaban a De las Casas en la capital episcopal del gran Michoacán ${ }^{31}$ le tenían por artista de calidad; sus prendas queretanas le merecieron de los canónigos de Valladolid la siguiente opinión:

"Alli se ha distinguido por sus magníficas, nombradas y pulidas obras: su destreza está en lo extraordinario de sus estructuras tan fijas y niveladas al arte, que no parece sino que la naturaleza así las crióm. ${ }^{32}$

30 A.C.C.M., Actas capitulares, Libro 27. Sesiones de 11 de enero y 17 de mayo de 1768 . No les faltaría razón a los capitulares para escribir a otros artífices si tomamos en cuenta que por aquellos años Querétaro, el Bajío de Guanajuato y el Potosi novohispano vivían momentos de gran esplendor artístico. Bastaría con mencionar la iglesia de la Compañia en Guanajuato, dedicada en 1765, la parroquia de Los Dolores, estrenada al parecer en 1757, o la iglesia del Carmen de San Luis Potosí. en la que se trabajaba ya en 1761. El gran Michoacán, cuatro informes del obispado de Michoacán, 1759-1769. Zamora, Mochoacán, 1986, pág. 36.

31 El antiguo obispado de Michoacán se extendía sobre los actuales estados de Michoacán, Guanajuato y partes de Guerrero, Jalisco, Colima, San Luis Potosi y Tamaulipas. El gran Michoacán. González Sánchez, Isabel: El obispado de Mi. choacán en 1765 . Morelia, 1986.

32 A.C.C.M., Actas capitulares, Libro 27. Sesión del 11 de enero de 1768. Según Tovar de Teresa (México barroco, pág. 166), con De las Casas y Gudiño so dio el auge del barroco en Querétaro. Al primero, que nació en 1719, atribuye Tovar la posibilidad de haber fabricado en aquella ciudad la iglesia y convento de San Agustín, dedicados en 1745. Sin embargo, el Extracto de las cartas e informes hechos por la ciudad de Querétaro a su señoria ilustrísima por el maestro don Ignacio Casas, que reproducimos en el apéndice (A.C.C.M., expediente de 1768), da cuenta de las principales realizaciones del artífice. El documento no está fechado, pero fue discutido por el cabildo catedral de Valladolid en marzo de 1760. No se mencionan la iglesia y convento de San Agustín eentre otras iglesias y conventos» atribuidos a De las Casas. Angulo Iñiguez opina que la atribución impone reservas; la iglesia de San Agustín fue comenzada en 1731 y por lo tanto, tendría que haberla trazado De las Casas a los once años de edad. Angulo Iñiguez, Diego: Historia del Arte Hispanoanericano. Barcelona, 1950, vol. II, pág. 739. Según el Extracto..., don Ignacio era fabricante de órganos, relojero, arquitecto, escultor y 
De las Casas formó mapa y montea para el altar mayor y al parecer gozaron del aprecio y estimación no sólo de los capitulares, sino hasta del obispo. En junio de 1768 dijo el artífice estar dispuesto a construir «no sólo el altar mayor y de reyes de esa iglesia, sino también la crujía, baptisterio y pila bautismal, todo por el mismo precio». ${ }^{33}$

Del tercer artífice, don Isidoro Vicente de Balbás, volvemos a tener noticias en 1768. Sus trabajos en la catedral de México le habían impedido asistir antes a Valladolid. Pero ahora el nuevo tesorero del cabildo, don Agustín Francisco de Esquivel y Vargas le pedía tener listo su diseño y enviar, además, una «abreviada copia del tabernáculo» que don Isidoro Vicente confeccionara en la catedral de México. ${ }^{34}$ Dicho de otra manera, los nuevos patrones tomaban en cuenta como modelo prestigioso la obra más reciente construida por Balbás en la catedral metropolitana: un altar mayor con su tabernáculo, seguramente el del sagrario.

En la sesión del cabildo catedral del 2 de mayo de 1768 se leyó una carta que describía el proyecto de Balbás para la catedral michoacana. Este consistía en la construcción del altar mayor y del retablo de reyes. Por el primero pedía 24.000 pesos y ejecutaría el segundo por 14.000. Al no tener con quien enviar los planos o mapas, aseguraba que esta vez sí podría llevarlos él mismo hasta Valladolid, sirviéndole el viaje a modo de paseo. ${ }^{35}$

Años de experiencia artística en Taxco y la ciudad de Mé-

retablista. Como se verá, trabajó en el colegio e iglesia de Santa Rosa de Queré taro desde alguna fecha anterior a 1755 , en que dejó funcionando allí dos órganos. Construyó un tercero para la iglesia de Nuestra Señora de Guadalupe, también en Querétaro. En 1761 seguía en Santa Rosa, donde echó a andar el reloj grande de la torre y ejecutó el tabernáculo para el Santísimo. Es probable que por esos mismos años De las Casas construyera dos bóvedas para el claustro de Santo Domingo, así como la capilla del tercer orden, más un tabernáculo. Para las religiosas capuchinas fabricó desde 1757 la nueva enfermería. el reloj grande y un sagrario. Y en el convento de Santa Clara construyó una bóveda en el coro para sepultura de las religiosas. En el convento del Pueblito De las Casas trabajó en el camarín de la iglesia, además de dos retablos para el convento. Por último, Francisco Gudiño dijo ser testigo de la habilidad artística de don Ignacio.

33 A.C.C.M., Actas capitulares, Libro 27. Sesión del 7 de junio de 1768.

34 Ibídem, Libro 26. Sesión del 16 de enero de 1765. Isidoro de Balbás al cabildo catedral de Valladolid.

35 A.C.C.M., Actas capitulares, Libro 27. Sesión del 2 de mayo de 1768. 
xico, ${ }^{36}$ además de una rica tradición retablística de origen andaluz perfeccionada por su padre adoptivo en Nueva España, confluyeron seguramente en el proyecto michoacano de Isidoro Vicente para que expresara lo que sigue:

“En término de tres años entregaré las dos obras perfectamente acabadas, con el nuevo uso y facilidad en el trabajo que he discurrido y pocos días hace tengo practicado en la especie de obras de esta naturaleza en que le será a esa santa Iglesia de mucho ahorro, grande lucimiento y poca dilatación». ${ }^{37}$

Si el dominio técnico hasta entonces alcanzado le permitía garantizar plazos reducidos y a menor costo en la hechura de sus obras, esto no iba en detrimento de la calidad de su plástica:

“En lo que dice a adornos, proporción y vista - comenta Balbás refiriéndose a su ciprés - tiene tanta y tan bien determinada, que junto lo uno con lo otro lo singularizan: las estatuas que tiene son muchos triunfos de ángeles, reinos y serafines; los adornos con que está vestido son de bastante capricho. Sus estípites logran una fantasía especial sin ningún desagrado y la trevesura de sus miembros carece de toda corrupción que ofusque o entor. pezca su buena arquitectura). ${ }^{38}$

De la presentación de Balbás se desprende que el proyecto que apenas concibiera para Valladolid de Michoacán fuese tal vez

36 Según Tovar de Teresa (México barroco, pág. 88), Isidoro Vicente de Balbás fue también autor del retablo mayor de la capilla del Rosario del convento de Santo Domingo de México, y de los retablos de la capilla de San Eligio en la catedral de México (1765). Consta además que presentó proyecto para los remates de la fachada de esta última. Sin embargo ya antes Concepción Amerlinck (Jeró-1 nimo de Balbás...). señaló que Balbás sólo se había obligado a ejecutar la obra en Santo Domingo de México por encargo de la archicofradía de Nuestra Señora del Rosario, pero que el contrato ano había pasado». Atentamente, Guillermo Tovar de Teresa me envió constancia documental de otras obras asimismo ejecutadas por Isidoro Vicente de Balbás: el retablo mayor y colaterales de la capilla del Señor de Contreras en el Carmen de San Angel y un colateral en la iglesia de la Santísima Trinidad de la ciudad de México.

37 Ibídem, Libro 26. Sesión del 16 de enero de 1765. Isidoro de Balbás al cabildo catedral de Valladolid.

38 Ibídem. 
el más ambicioso de su trayectoria artística, según expresó el propio artífice al cabildo catedral al hacerle patente su trabajo:

"Que aunque parezca pasión o vanidad, es digna de todo aprecio y en lignea de tabernáculo hay tanta diferencia del dibujo que tengo hecho a lo que practicamos en esta metropolitana, que será el que tengo deligneado para esa iglesia, puesto en ejecución, una de las cosas más apreciables que tenga este reyno y sin duda se llevará el aplauso y aclamación entre todos los de las catedrales y tomándome alguna más licencia, podré asegurar podría competir con el de más estimación que haya en las catedrales de Europa). ${ }^{39}$

Al final de la sesión del 2 de mayo de 1768, el capítulo diocesano decidió hacer venir tanto a Ignacio de las Casas como a Isidoro Vicente de Balbás para que, viendo la iglesia catedral, hicieran las últimas propuestas del precio calculado respectivamente para el altar mayor y el de reyes. El 14 de junio algunos prebendados convinieron en contar con la licencia del virrey marqués de Croix para iniciar las obras, pues había confusión entre los caudales de fábrica y los de espolios de obispos. Sin embargo, la mayoría del cabildo opinó que la autorización del virrey no era necesaria. ${ }^{40}$

Entonces se procedió a la votación del maestro o artífice para la fábrica de los altares. Se manejaron por igual ambos nombres, Ignacio de las Casas e Isidoro de Balbás, pero ante la diversidad de pareceres se acordó poner el negocio directamente en manos del obispo Sánchez de Tagle. ${ }^{41}$ Días después, éste mandó noticia a su cabildo de no poder resolver tan pronto tocante a esta materia. En diciembre de 1768 el prelado, que al parecer se inclinaba más por el proyecto de De las Casas, mandó que las cartas e informes de éste fueran nuevamente leídas en sesión del cabildo. ${ }^{42} \mathrm{~A}$ suge-

39 Ibidem.

40 A.C.C.M., Actas capitulares, Libro 28. Sesión del 14 de junio de 1768.

41 Ibjdem. También en Mazín, Entre dos majestades..., capitulo tercero.

42 A.C.C.M., Actas capitulares, Libro 28. Sesión del 14 de junio de 1768. 
rencia de algún prebendado, el proyecto delascasiano debía enviársele a México a don Isidoro Vicente de Balbás para oír su dictamen, antes de saberse el resultado del concurso.

\section{El VEREDICTO}

La contratación de obras para el culto religioso en la catedral michoacana y en otras mantuvo el criterio de un máximo ahorro de recursos. Así, mediante la oposición de varios artífices para la ejecución de una misma obra se promovía la competencia, se elevaba la calidad artística y se regulaban los costos. Esta tendencia al ahorro se explica en parte por la creciente supervisión que ejercía la Corona sobre los dineros eclesiásticos. Por real cédula de 23 de mayo de 1769 se encargó a las iglesias presentar todos los años al virrey una minuciosa relación de ingresos y egresos del ramo de fábrica. Debían reducirse a toda costa, según advirtiera el virrey marqués de Croix, el dispendio y los gastos superfluos. ${ }^{43}$

De la iglesia de Michoacán se esperaba el más estricto acatamiento, y se le urgieron las cuentas, «sin que por parte de ese cabildo se dé lugar a la menor falta». ${ }^{44}$ En consecuencia, el cabildo catedral acordó disimular la importancia de la ornamentación de su catedral. Por lo tanto se minimizó este gasto justificándolo y se formaron las cuentas «con el cargo y data de lo que se recibe y expende en gastos forzosos, cuyo sobrante a favor de la fábrica se diga tenerse destinado para las obras pendientes de colaterales, crujía y demás». ${ }^{45}$

Por esta razón debieron silenciar las actas del cabildo el resultado del concurso de oposición.

43 A.C.C.M., Actas capitulares, Libro 28. El virrey al obispo, deán y cabildo de Michoacán. Sesiones del 13 y 26 de agosto de 1768. A.C.C.M. Actas capitulares, Libro 28. Sesión del 16 de noviembre de 1769. El marqués de Croix al cabildo catedral de Valladolid. 11 de noviembre de 1769. Años más tarde se confirmaría esta política. Carlos III prohibió que los grandes retablos de las iglesias de América se construyeran utilizando maderas doradas. Obregón, Gonzalo: Barroco estipite, «Artes de México», núm. 106, México, 1968, págs. 40-4,2.

44 A.C.C.M., Actas capitulanes, Libro 28. Sesión del 16 de noviembre de 1769.

45 A.C.C.M., Aclas capitulares, Libro 29. Sesión del 29 de mayo de 1770. 
Por una breve cuenta dada años después sabemos que se contrató a Ignacio Mariano de las Casas. Tal vez porque el precio que diera para el conjunto de las obras fuese más bajo que los de Balbás. En 1769 se le encomendaron la pila y bautisterio, y en una carta al tesorero Agustín Francisco de Esquivel y Vargas, registrada el 16 de febrero de 1770, De las Casas «le satisface sobre la rectitud del mapa y su arreglada montea que tiene formada para el altar mayor, calificándola con las aprobaciones que ha tenido de otros maestros peritos en el arte, de México y Querétaro». Además pedía dinero para habilitar casa y taller donde trabajar las maderas que se habían traído a la catedral, «y se mandó expedir decreto a los claveros para ministrar al tesorero lo necesario». ${ }^{46}$

Por lo que hace a la pila o fuente bautismal de plata, De las Casas propuso hacerle un pedestal de «similiplata». Pero «hizo un pedestal tan indecente que parecía de plomo y se perdió el dinero». ${ }^{47} \mathrm{Al}$ parecer, el bautisterio tampoco llegó a ejecutarse. En cambio es muy probable que De las Casas hubiese comenzado a fabricar el altar mayor, y que a su muerte, en 1772, éste quedara interrumpido. ${ }^{48}$ Se retomaría casi inmediatamente, pues en 1773 la junta de obras pendientes habló del «tabernáculo de plata que ostentaría el nuevo ciprés». Existía ya una custodia o tabernáculo viejo, también de plata, que se enviaría a México para que un orfebre lo reformara, pues «no está tan hermoso como corresponde

46 Archivo Capitular de Administración Diocesana, Valladolid-Morelia. (En adelante A.C.A.D.V.M.), caja 47, legajo único. Expediente sobre las cuentas de pila y baptisterio presentadas por el br. don Pedro García Botello, como albacea del sr. tesorero Dr. Dn. Agustín de Esquivel. La última fecha de este documento es la de 23 de octubre de 1783 . A.C.C.M., Actas capitulares, Libro 29. Sesión del 1 de febrero de 1770. En esa fecha se supo en sesión de cabildo que ya había visto Isidoro de Balbás los planos de Ignacio de las Casas. Balbás «expuso menudamente los defectos de que adolecía su proyecto. En consecuencia, el cabildo catedral acordó que los planos delascasianos pasaran cuanto antes a la calificación de sujetos peritos. A.C.C.M., expediente de 1768, Extracto.... Cabe la posibilidad de que el otro maestro perito de Querétaro de quien hablaba De las Casas fuera el mismo Francisco Gudiño, quien decía conocer sus habilidades como artiflce.

47 A.C.A.D.V.M., caja 47, legajo único. Expediente sobre las cuentas de pila y baptisterio... en 1772 .

48 Según Tovar de Teresa (México barroco, pág. 248), el artista murió 
a la nueva fábrica, ni se puede acomodar a los tamaños y medidas de ella». ${ }^{49}$ De todas las obras fue precisamente el altar mayor la primera en estrenarse el 6 de agosto de 1774 .

Al desaparecer de la escena De las Casas, debió contratarse un nuevo maestro mayor que terminara el altar mayor y ejecutara el altar de reyes, además de la nueva crujía de plata. El mapa o dibujo para el altar de reyes fue aprobado en la junta de obras pendientes del cabildo, el 4 de agosto de 1773, a poco más de un año de haber fallecido el obispo Sánchez de Tagle. Se construiría según el modelo de Isidoro Vicente de Balbás y su ejecutor sería el artífice Francisco Gudiño. ${ }^{50}$ Según cuenta que presentó Bartolomé Castillo, maestro de herrería, Gudiño fue el maestro mayor de las obras hasta su conclusión en 1776 y fue su sobrestante Nicolás Baquero. ${ }^{51}$

Próximo a celebrarse el día del Salvador del año 1774, se mandó estrenar el nuevo altar mayor a iniciativa del nuevo obispo, don Luis Fernando de Hoyos y Mier. El ciprés estaba casi acabado y sólo le faltaba el tabernáculo o custodia, «cuya obra con la dicha crujía había quedado el platero de entregarla dentro de 10 meses». ${ }^{52} \mathrm{La}$ posibilidad de esperar para celebrar un estreno conjunto de ciprés, crujía y altar de reyes fue rechazada por parecer un tiempo demasiado largo al obispo y cabildo. Por lo tanto se estrenó el altar mayor con las funciones de la fiesta titular de la catedral, la transfiguración, el sábado 6 de agosto de 1774 .

La crujía y el altar de reyes se estrenaron más tarde. La, primera fue ejecutada por el platero Francisco Rivera, quien sustituyó la vieja baranda de bronce por una de plata que llevaba estatuas a cada lado e iba montada sobre sotabancos y zoclos de

49 A.C.C.M., Actas capilulares, Libro 30. Sesión del 4 de agosto de 1773. Esta noticia se refiere muy probablemente a la custodia procesional comúnmente conocida como «manifestador» y que se muestra en el actual ciprés de la catedral de Morelia.

50 Ibídem.

51 A.H.M.C.R., Casa de Morelos. Negocios Diversos, Legajo 89, 1776. Cuenta que yo Bartolomé Castillo, vecino de esta ciudad y maestro de herrería en ella. doy al si. dn. Mariano Antonio de la Vega... dignidad arcediano de resta Santa Iglesia...

52 A.C.C.M., Actas capitulares, Libro 31. Sesión del 2 de agosto de 1774. 
cantería. Asimismo, se repararon las puertas y lados del coro, y sc pusieron escudos al parecer en el antepecho y copetes de su reja. ${ }^{53}$ En septiembre de 1776 el doctor Mariano Antonio de la Vega, quien fungiera como superintendente de las obras «nuevamente hechas de altar mayor y Reyes y tabernáculo del Divinísimo», entregó las cuentas al cabildo. Todo ascendía a 87.882 pesos, 1 real. $^{54}$

El Ciprés de Isidoro Vicente de Balbás

Al final de este artículo aparecen dos documentos escritos por Isidoro Vicente de Balbás. El primero es la carta dirigida al cabildo catedral de Valladolid, sin fecha, en que el artífice hace un recuento de las ocasiones en que fuera requerido para presentar su proyecto. Luego de hablar del impedimento para ir personalmente a Michoacán, pasa a ponderar las virtudes de sus propios planos y también nos informa que había visto ya los de De las Casas. Dicha carta fue discutida en la sesión capitular del 1 de febrero de 1770, por lo cual debe ser poco anterior a esa facha.

El segundo testimonio es una descripción somera hecha por el propio Balbás de su diseño para el ciprés de la catedral y tam: bién ocupó la agenda del capítulo diocesano durante el acuerdo del 1 de febrero de 1770 . No ha sido posible determinar si se escogió este modelo; según vimos, sólo se hizo constar por escrito que el tabernáculo de plata antiguo resultaba inadecuado para la nueva fábrica del altar mayor.

Esta referencia permite considerar que el uso principal del ciprés era el de albergar el tabernáculo de plata para el Santísimo. En su artículo sobre el altar mayor de la catedral de México, ${ }^{55}$ Elena Estrada de Gerlero inscribe los altares mayores exentos sobre el presbiterio en la tradición de las enormes custodias procesionales

53 A.C.A.D.V.M., caja 47, legajo único. Expediente sobre las cuentas de pila y baptisterio...

54 A.C.C.M., Actas capitulares, Libro 32. Sesión del 6 de octubre de 1777.

55 Estrada de Gerlero, Altar mayor.... 
labradas en forma de templetes. Las hace remontar hasta mediados del siglo XV, cuando el papa Eugenio VI confirmó en 1443 «el carácter triunfal y alegre de la fiesta del Corpus». ${ }^{56} \mathrm{Y}$ así explica que «fueron precisamente las custodias procesionales las que inspiraron estos altares exentos, como si hubieran echado raíces y hubieran crecido en el presbiterio formando el «ciprés» que, con su anhelo ascensional, expresa el símbolo asociado al altar que es la unión entre el cielo y la tierra». ${ }^{57}$

El ciprés que proyectara Isidoro Vicente de Balbás para la catedral de Valladolid tomó en cuenta no sólo aquel que recientemente fabricara para el sagrario de la catedral metropolitana, sino también el que su padre adoptivo, Jerónimo de Balbás, construyera en 1742 para aquella iglesia. Don Jerónimo contempló no sólo el empleo de las pilastras estípites que lucieran por lo menos desde 1725 en su espléndido retablo de reyes, sino también el tabernáculo de plata maciza que mandara hacer el arzobispo Vizarrón y Eguiarreta con el metal de sus vajillas. ${ }^{58}$

Veinticinco años después, Isidoro Vicente delineaba para Valladolid de Michoacán un ciprés de base cuadrangular de unos quince metros de alto, con cuatro frentes, dos cuerpos y un remate. Seguían apareciendo en los ángulos cuatro pilastras estípites monumentales, en virtud de la notable influencia que ejercían, como símbolos de gran prestigio, el altar mayor y de reyes de la catedral metropolitana. Recuérdese que desde un principio el obispo Sánchez de Tagle recomendó tomar diseño del altar mayor de la catedral de México. Así pues, el estípite metropolitano como gran signo formal del barroco penetraba en la catedral michoacana.

Por lo que hace a la insistencia del artífice en el número, cuatro, en ello quedaba implícito el respeto a la tradición que asocia el cuadrado perfecto a la prefigura de la iglesia, la Jerusalén celeste a la que hace referencia el libro del Apocalipsis:

56 Ibidem, pág. 454.

57 Ibídem. pág. 456.

58 Ibídem, pág. 460. 
"Y vi la ciudad santa, la nueva Jerusalén, que descendía del cielo al lado de Dios, ataviada como una esposa que se engalana para el esposo. Oí una voz grande que del trono decía: he aquí el tabernáculo de Dios entre los hombres, y erigirá su tabernáculo entre ellos, y serán su pueblo y el mismo Dios será con ellos, y enjugará las lágrimas de sus ojos y la muerte no existirá más ni habrá duelo... me mostró la ciudad santa, Jerusalén, que descendía del cielo... la ciudad estaba asentada sobre una base cuadrangular y su longitud era tan grande como su anchura...). ${ }^{59}$

Coronando cada una de las estípites monumentales de los ángulos irían los cuatro doctores de la Iglesia latina: San Jerónimo, San Agustín, San Ambrosio y San Gregorio Magno, o bien los santos que el cabildo eligiese. En el primer camarín, especie de nicho formado por cuatro arcos cuyas impostas se desprenden de ocho estípites menores, iría la propia custodia procesional de plata para el Santísimo; coronaban los cornisamientos numerosos reinos, es decir, angelillos, con insignias de los patriarcas que prefiguraron al Mesías prometido.

Sobre el segundo cuerpo y en ascensión cada vez más disminuida y delicada, ocho medias estípites flanquearían el siguiente camarín. Les adornaban medallones con «serafines de caprichosa idea», y al pie de cada una de las dichas medias estípites aparecían dos mancebos con espigas de trigo alusivas al sacramento de la Eucaristía que Jesucristo dejara instituido como signo de la nueva alianza. Este segundo camarín debió ostentar alguna imagen de Jesús Salvador, advocación principal de la catedral hasta hoy en día, y que se representa con la escena de la Transfiguración. Esto se debe a que precisamente con este misterio ha conmemorado la Iglesia desde antiguo el día del Salvador. Se conformaría así una correspondencia iconográfica con la fachada de la catedral, cuyo relieve central representa a Cristo transfigurado. Lo mismo ocurre en la catedral metropolitana, aunque en el retablo de los reyes,

59 Ibídem, pág. 457. 
donde un gran lienzo reproduce el tema central de la fachada: la Asunción de la Virgen María.

Coronaban las medias estípites del altar vallisoletano los siete príncipes de la luz o categoría angélica de la cual el calendario germánico registra ocho nombres: Miguel, Gabriel, Rafael, Uriel, Malthiel, Zadkiel, Peliel y Raziel. ${ }^{60}$ Para completar el número de ocho estípites sugería Balbás poner «al santo ángel custodio», fiel protector así de individuos como de pueblos.

Venía por último el remate adornado por los cuatro lados con ángeles y serafines, de gusto muy balbasiano, «formando una graciosa tarjeta en la que están las armas de san Pedro ${ }^{61}$ y sobre ésta el triunfo de la fe, virtud teologal representada posiblemente por una imagen vendada como verdadero coronamiento del misterio de Jesús Salvador, tema central, como hemos visto, de este ciprés de Valladolid de Michoacán.

\section{EPílogo}

Las realizaciones del proyecto catedralicio aquí relatadas correspondieron al aspecto litúrgico de un régimen de gobierno y administración diocesanas. El momento era el de una crisis de convivencia con la potestad temporal debido sobre todo a un endurecimiento de la política eclesiástica de la Corona.

Expresado en términos de una constante presión fiscal, tal endurecimiento amenazó en momentos con vulnerar la relativa autonomía administrativa de la catedral michoacana. A contracorriente, el obispo y su cabildo optaron por una política de gasto echando mano de los fondos del ramo de fábrica.

El proyecto que concibieran para ejecución de los altares mayor y de reyes, más la crujía, fue el de mayor envergadura de cuantos ocuparon la agenda del cabildo eclesiástico en el período

60 Enciclopedia Universal Ilustrada Europeo-Americana. Madrid, 1980, tomo $\mathrm{V}$, ver «Angel».

61 A.C.C.M., legajo correspondiente a 1770. Descripción del ciprés para la catedral de Valladolid de Michoacán. 
que va desde la consagración de la iglesia catedral en 1705, hasta por lo menos el año 1780 . Se trataba de una magna obra que se proponía dignificar estéticamente los espacios de mayor categoría en el recinto catedralicio: el altar mayor o trono de Cristo, corazón del conjunto arquitectónico, y la capilla real que evocaba el importante patrocinio del rey sobre las iglesias de las Indias.

Para aquella sociedad la erección de un altar mayor o el enriquecimiento de alguna costumbre litúrgica eran hechos sociales de relevancia. Mucho nos diría el estudio de las fundaciones piadosas de aquellos años, de sus devociones 'y su ceremonial reflejado en sus realizaciones plásticas correspondientes. Seguramente éstas contribuyeron a reforzar las tradiciones religiosas locales.

Ahora bien, desde el punto de vista de los saberes que se iban trasmitiendo en el cabildo sobre sistemas de oposición, peritaje y contratación de los artífices, es decir de la tradición artística de la plástica, extraña que para efectos del proyecto en cuestión no hubiesen acudido maestros oriundos de Valladolid o siquiera residentes en ella. Más bien se contrataron artistas queretanos de renombre.

En cambio por lo que hace a modelos, la influencia más prestigiosa fue sin duda la proveniente de la catedral metropolitana. En la etapa preparatoria del proyecto se pidieron modelos en Puebla y México, y fue el de Isidoro de Balbás, maestro de la iglesia metropolitana, el de reconocida superioridad; no sólo por habérsele pedido que enviara los planos de la obra que apenas realizara en el sagrario metropolitano, sino al someter a su juicio el proyecto del maestro queretano De las Casas.

Francisco Gudiño trabajó el altar de los reyes sobre el modelo de Isidoro de Balbás. Pero cabe la posibilidad de que lo mismo hiciera con el altar mayor Ignacio de las Casas a partir de 1770', sobre todo luego de su fracaso con la pila bautismal y al haber expuesto Balbás «menudamente los defectos de que adolecía» el proyecto delascasiano para el ciprés.

El altar de reyes que estuvo en el ábside hasta mediados del siglo XIX debe atribuirse en definitiva a la inspiración de Isidoro Vicente de Balbás. Al perder sentido el patronazgo real, 
y por tanto la capilla real, no volvemos a tener noticias referentes al ábside hasta 1898. Para entonces el arzobispo José Ignacio Arciga y Ruiz de Chávez mandó reformar la decoración interior de la catedral.

Este prelado consultó el parecer del cabildo para que se quitara el viejo altar de los reyes, ya que «afeaba la vista del nuevo ciprés» que es el que hoy apreciamos. Fue ejecutado por el superintendente de las obras de la catedral, don Claudio de Molina. He aquí el contenido de dicha argumentación:

“Bastará una simple vista de ojos desde el centro de la nave principal para palpar desde luego el malísimo efecto que producen las pilastras y cornisas que quedan del altar de los reyes, sirviendo de fondo al magnífico y elegante panteón que se ha levantado en el presbiterio". ${ }^{62}$

Ya antes se había puesto un enorme cortinaje para fondo del ciprés anterior estrenado en 1845 . Este era pesado y contaba con veinte columnas tan sólo en su primer cuerpo. ${ }^{63} \mathrm{El}$ nuevo ciprés de ocho columnas, más esbelto, dejaba un mayor campo visual sobre los restos del altar de reyes. Dichos restos, según el arzobispo Arciga, «producen el óptico desconcierto y deslustran la unidad arquitectónica del conjunto». ${ }^{64}$ Por lo tanto prometió el prelado utilizarlos para modificar el altar del sagrario, dedicándolo al Sagrado Corazón de Jesús que hasta entonces no tenía colocación alguna en la catedral.

Las razones de Arciga, encaminadas a lograr un sentido de unidad y armonía estilísticas, por fin se impusieron al cabildo eclesiástico. Este retiró su oposición inicial y aceptó que los muros del ábside quedaran libres, ya sin el altar de reyes.

Oscar Mazín

62 A.C.C.M., Actas capitulares, Libro 71. Sesión del 1 de junio de 1898.

63 Ibídem. Véase además, González Galván, Una glosa reconstructiva ideal. El antiguo ciprés barroco de la catedral de Monelia. Reproduce este trabajo una fotografía antigua del ciprés, de gusio neoclásico.

64 Ibidem. 


\section{APENDICE}

\section{Documento 1}

Muy ilustre venerable señor deán y cabildo

Don Isidoro Vicente de Balbás, vecino de México y maestro de la santa iglesia metropolitana. Puesto a los pies de vuestra señoría en la mejor forma que haya lugar, digo que habiendo tenido noticia de que vuestras señorías han resuelto principiar el tabernáculo y altar de reyes, para lo que mandaron disponer taller previniéndose de maderas y otros necesarios para esta construcción.

A la que siendo uno de sus pretendientes y teniendo ejecutado mapa por expreso orden de el señor doctor Nájera (años hace) y el año de sesenta y cinco por el señor doctor don Ricardo Gutiérrez Coronel al mismo fin, aunque con más expresiva prevención, precisándome a que me transportase a esa ciudad en términos de un mes, para que en conjunción de otros artífices asimismo pretensores se definiese elección.

Y no habiéndome permitido el ilustrísimo señor arzobispo doctor don Manuel Rubio y Salinas viajase, aun teniéndole finalizada la obra que a su ilustrísima hice en el sagrario de la catedral. [Díjome] cuando tomé su venia para partirme a esa ciudad, el que escribiría sobre el particular y que vuestras señorías no le negarían la espera ínterin finalizaba yo algunas cosas de poco monto de tiempo que su ilustrísima pretendía hacer para más adorno de su obra; y que asimismo insinuaría a vuestras señorías el desempeño de mi obligación una vez que librasen en mí sus confianzas.

Por carta del señor doctor don Agustín Francisco Esquivel y Vargas con fecha de diez y siete de febrero del año de sesenta y ocho, me instruye dicho señor la intención de vuestras señorías en la construcción del ciprés y altar de reyes para su debido efecto y como pretensor me 
previene apronte diseño, encargándome una abreviada copia del tabernáculo que tenemos hecho en esta santa iglesia.

Por otra carta, no sé si de orden de vuestras señorías o encargo que se haría a algún señor capitular de esa santa iglesia escrita a don Manuel Cano, apoderado de vuestras señorías, en la que se le encarga diese yo respuesta a los puntos que dicho sujeto me hizo saber. Y también a que diese mi parecer sobre un mapa que vino delineado por don Ignacio de Casas, vecino de Querétaro (también pretensor) a que respondí por dicho apoderado, como constará en ese archivo y secretaría.

Supuestas todas estas prevenciones que llevo relacionadas, ocurro a vuestras señorías deseoso de servirles, por lo que hago patente el trabajo que he tenido en delinear y discurrir una cosa que aunque parezca pasión o vanidad, es digna de todo aprecio. Y en línea de tabernáculo hay tanta distancia y diferencia del dibujo que tengo hecho a lo que practicamos en esta metropolitana, que será el que tengo delineado para esa iglesia, puesto. en ejecución, una de las cosas más apreciables que tenga este reino y sin ninguna duda se llevará el aplauso y aclamación entre todos los de las catedrales. Y tomándome alguna licencia podría asegurar podrá competir con el de más estimación que haya en las catedrales de la Europa.

Me he excedido mucho en ponderarlo si me remito a las obras bajo el supuesto de ser humilde y faltarme mucho que saber. Me he excusado de remitirlo atento a haber aguardado orden de vuestras señorías y estar esperándola para ponerme en camino y concurrir con los artífices pretensores, de quienes espero ver acertadas delineaciones.

El diseño que yo presentaré tiene las conveniencias que se solicitan para su manejo, que es una de las más apreciables. Y entre lo más que tiene se le agregan su acomodo en el poco ámbito de su presbiterio y libre desembarazo, sin perjuicio a la nave frontera al altar de los santos reyes, dejando libre amplitud para poder celebrar misa. En lo que dice a adornos, proporción y vista, tiene tanta y tan bien determinada, que junto lo uno con lo otro lo singularizan: las estatuas que tiene son muchas; muchos triunfos de ángeles, reinos y serafines. Los adornos con que está vestido son de bastante capricho, sus estipites logran una fantasía especial sin ningún desagrado. La travesura de sus 
miembros carece de toda corrupción que ofusque o entorpezca su buena arquitectura.

Y haciéndome cargo de todas estas calidades referidas puedan ser a vuestras señorias incentivo para que yo en servicio de esa santa iglesia tome el camino y se las inanifieste una vez que vuestras señorías me lo manden, obedeceré con la ciega voluntad con que apetezco servirlos, sin el mayor interés que pudiera sobrevenirme.

Y habiéndoseme proporcionado poner en manos de vuestras señorias este escrito por don Jorge Atanasio de Zúñiga quien intenta regresarse a esa ciudad, asimismo podrá decir a vuestras señorías sobre el particular lo que tiene visto; y con la inteligencia que tiene, relacionará lo que yo omito por no cansar más la atención de vuestras señorías, si digo que en término de tres años entregaré las dos obras perfectamente acabadas, con el nuevo uso y facilidad en el trabajo que he discurrido y pocos días hace tengo practicado en la especie de obras de esta naturaleza en que le será a esa santa iglesia de mucho ahorro, grande lucimiento y poca dilación.

A vuestras señorias pido se sirvan mandar lo que en este asunto fuere de su mayor complacencia, que será de mi mayor aprecio.

Isidoro Vicente de Balvás [rúbrica].

\section{Documento 2}

Descripción del altar mayor o ciprés

El presente mapa hecho por don Isidoro Vicente de Balvás tiene de alto diez y seis varas y su ancho por todos sus cuatro lados es el de cuatro varas en cuadro. Contiene muchas estatuas de santos reinos y serafines. Logra una especial colocación y determinación de sus miembros, como lo manifiesta su alzado.

Lleva cuatro puertas, la una puede servir de entrada para el manejo del primero camarín y para el segundo, como asimismo para su remate. Las otras tres podrán servir de alacenas con el mediano campo que ofre- 
ce el espacio de la regular distribución de los seguros para su firmeza. Tiene en sus ángulos determinada subida para su uso, la que se puede regular y ver por su planta. Esta es sin ningún peralte de escalones, que si los llevara sería dilatar más el espacio en que se halla determinada y embarazaría lo interno del primero y segundo camarín que no es necesario.

Lleva en los cuatro frentes de su primero y segundo cuerpo los pabellones que ofrecen su diseño, que en caso de oscurecer sus interiores podrán omitirse o elevarse para estorbar esta reflexión.

Tiene cuatro estípites grandes en sus ángulos, sobre los que rematan en su coronación los cuatro doctores o los santos que el venerable señor deán y cabildo tuvieren por conveniente.

En el primer camarín reciben sus cuatro arcos, sirviéndoles de impostas las ocho coronaciones de los estípites que guarnecen el empilastrado de sus muros, sobre las que se ven figurados ocho frontis que tienen su arranque de la corona que cubre el banquillo de dichas cornisas, sobre los que se miran adornados cada uno con dos reinos con atributos $o$ insignias de cada uno de los santos patriarcas que en dicho lugar se ven figurados, los cuales van opuestos a los arbotantes que se gozan por sus lados.

De bastante follaje y gustosa talla, siguense correlativamente los nismos miembros disminuidos, especialmente en la formación de sus ocho medios estípites que se hallan inmediatos al segundo camarín del Salvador. Estos están adornados con medallas, serafines y cortejos de caprichosa idea. Al pie de los dichos están en cada uno de ellos dos mancebos con espigas de trigo alusivas al divino sacramento. Sobre las coronaciones de los dichos se dejan ver los siete príncipes y para completar los ocho lugares se podrá colocar el santo ángel custodio.

Síguese el remate adornado con la misma fachada que muestra su delineación en sus cuatro lados, de ángeles, serafines y adornos de talla caprichosa formando una graciosa tarjeta en la que están las armas de san Pedro. En las tres de su mismo tenor se puede diferenciar con las armas de la iglesia o con las que parezca más del agrado del venerable señor deán y cabildo. Remata sobre dicha tarjeta el triunfo de la fe, con el acompañado de ocho ángeles con palmas y ramos de oliva. 
Los cuatro depósitos omito relacionarlos, por lo muy patente que se dejan ver en su delineación, pues en él se muestra lo claro, vistoso y agradable de su construcción.

En lo que dice a precio, me remito a la exposición que tengo presentada al muy ilustre venerable señor deán y cabildo, dudando el manejo que pueda haber en esa ciudad con los operarios y costos de maderas, el que una vez informado de todo, haré lo que sea del agrado de dichos señores sin ningún perjuicio mío. Por tanto lo firmé.

Isidoro Vicente de Balvás [rúbrica]

\section{Documento 3}

Extracto de las cartas e informes hechos por la ciudad de Querétaro a su illma. por el maestro don Ignacio Casas.

Carta del vicario del colegio de Santa Rosa.--el bachiller don Juan Joaquín de Zárate, vicario y capellán del colegio de Santa Rosa, expone en su carta sobre la fábrica de un órgano de singular dibujo y talla con catorce mixturas, con tan singular artificio para alzar los fuelles, que sentadas dos niñas con una rueda los alzan, que son cuatro grandes y está sirviendo desde el año de cincuenta y cinco. Con esto se ocurrió al daño que las que los alzaban se lastimaban el pecho. Otro hizo de siete mixturas en dicho colegio.

Otro en la iglesia de nuestra Señora de Guadalupe de especial montea y artificio, con flautas de metal tan sólido que aunque se siente un hombre sobre ellas no se doblan, con cincuenta y una tecla y otras circunstancias primorosas.

Relojes ha hecho varios. El reloj grande de Santa Rosa (que también hizo otro pequeño) le adornan circunstancias que no hay otro en el reino. Es de repetición a cada cuarto hasta la hora inmediata. Tiene tres muestras a los tres frentes de la torre que miran a la calle y andan parejos. Tiene cuerda para ocho días, y sus pesas de veinticuatro arrobas. Ie dan cuerda las niñas aunque sean de diez años y está sirviendo desde el año de sesenta y uno. 
Hizo el tabernáculo del Santísimo de rayos de reflejo y de vidrios azogados. El trono de Santa Rosa también de vidrio azogado y talla dorada de pulimento, ambas piezas de especial monteo; un monumento de singular vista y distribución.

Concluye que el dicho don Ignacio es de tan rara capacidad y habilidad que no emprende cosa que no consiga y a nada se le of rece imposible que no venza.

Carta del R. P. fray Manuel Castellanos, prior de Santo Domingo.- - expone la construcción de dos bóvedas en claustro y escalera, esquifadas y planas sobre muros antiguos y débiles. La capilla del tercero orden en corta situación, surtida de oficinas necesarias con que está fortaleciendo la iglesia grande y el convento; muy pulidas y de curiosidad vistosa. Hizo un curioso tabernáculo de cristal. Fundió campanas con otras operaciones en las iglesias y conventos partos de su ingenio.

Carta del bachiller don Diego de Zegovia, prefecto de la Congregación de Guadalupe.-expone la gran capacidad del sujeto, singular ingenio y procederes acreditados con muchas obras en la ciudad y fuera de ella y aceptación de los interesados. En las obras que ha hecho por encargo de la Congregación ha salido con perfección y con mucho menor costo que si hubiera corrido por otro.

Carta de la reverenda abadesa de religiosas capuchinas, su vicario y capellán. - expone apasionada y agradecida que hizo la nueva enfermería con la comodidad y alivio que permite su instituto, con el reparo de otras piezas con hermosa singularidad de bóvedas con fortaleza y duración. El reloj grande con poca ayuda de vecinos. Un sagrario para el que dieron los bienhechores setecientos pesos para ayuda de oficiales; salió de más crecido precio, a especial gusto de los bienhechores y concluye que es general para todo.

Informe de la madre abadesa de Santa Clara.--expone una bóveda en el coro para sepultura de las religiosas, cuya fábrica es aplaudida 
de todos los que la han visto, con otras obras a gusto y satisfacción del convento como de los de afuera.

Carta del R. P. guardián de los descalzos, fray Silvestre García.da en ella las gracias a don Ignacio de su dirección tan acertada en el reparo de la obra del dormitorio nuevo por idea suya, cuando los más inteligentes artífices la amenazaban de próxima y espantosa ruina, de cuyos peligros libertó don Ignacio al convento.

Carta informe del R. P. guardián del Pueblito, fray Antonio Solchaga.- expone larga experiencia de la destreza de don Ignacio con que reduce a práctica las vivisimas ideas que consigue y son patentes en el camarín de aquella iglesia en el arte con que la imagen de nuestra Señora (antes fija) diese vuelta a dejarse ver el rostro por la parte de su camarín, facilitando por esa parte el manejo de la imagen, sin su manoseo y sin abrir dicha vidriera. Dos retablos muy pulidos, acomodándose a las cortas facultades del convento, sobrándole alcances a la idea del artífice. Concluye que es muy cabal y diestro al cumplimiento de cualquier obra.

Finalmente, don Francisco Gudiño, en una esquela escrita al dicho don Ignacio, en que le asienta ser perpetuo predicador de su rara habilidad en el arte.

Todas las firmas de los referidos informantes vienen certificadas y reconocidas por el escribano público. Las obras mencionadas en este extracto si se evalúan, no hay duda que pasarán de sesenta mil pesos. Y los interesados no habían de exponer los caudales sin conocimiento de la integridad del sujeto. 